\title{
IMPROVING HANDS-FREE SPEECH REHABILITATION IN LARYNGECTOMIZED PATIENTS: PRELIMINARY RESULTS OF A NOVEL INTRATRACHEAL FIXATION DEVICE
}

\author{
Maartje Leemans \\ Dept. Head and Neck \\ Oncology and \\ Surgery \\ The Netherlands \\ Cancer Institute \\ Amsterdam, NL
Edsko E.G. Hekman
Dept. Biomechanical
Engineering
University of Twente
Enschede, NL

\author{
Maarten J.A. van \\ Alphen \\ Dept. Head and Neck \\ Oncology and Surgery \\ The Netherlands Cancer \\ Institute \\ Amsterdam, NL
Michiel W.M. van den Brekel
Dept. Head and Neck
Oncology and Surgery
The Netherlands
Cancer Institute
Amsterdam, NL

\section{ABSTRACT}

Permanent hands-free speech with the use of an automatic speaking valve (ASV) is regarded as the optimal voice rehabilitation after total laryngectomy. Due to fixation problems, regular ASV use in laryngectomized patients is limited. We have developed a novel intratracheal fixation device (ITFD), composed of an intratracheal button augmented by a hydrophilic PVA foam exterior around its shaft. The aim of this study was to evaluate the ITFD's feasibility in vitro, defined as an effective ASV fixation without causing mucosal tissue traumatization.

We found that when the expanded PVA foam is compressed less than $60 \%$ of its original thickness, it can potentially provide both a safe and effective ASV fixation in a range of tracheostoma morphologies; enough fixation to withstand pressures related to loud speech (approximately $6 \mathrm{kPa}$ ) without exerting excessive pressure (>32 $\mathrm{mmHg}$ ) which could lead to ischemic damage to the tracheal tissue.

This study demonstrates the feasibility of the ITFD in vitro that might improve stomal attachment of ASVs. The ITFD's deformable foam exterior may provide an effective fixation in most laryngectomized patients, compared to commercially available fixation methods, without the need for a user-specific customization. The results of a clinical feasibility study in laryngectomized patients are pending.

\author{
Richard Dirven \\ Dept. Head and Neck \\ Oncology and Surgery \\ The Netherlands Cancer \\ Institute \\ Amsterdam, NL
}

\author{
Gijsbertus J. Verkerke \\ Dept. Biomechanical \\ Engineering \\ University of Twente, \\ Enschede, NL
}

Keywords: total laryngectomy, speech rehabilitation, hands-free speech, intratracheal fixation, tracheostoma valves, automatic speaking valve

NOMENCLATURE
$\begin{array}{ll}\mathrm{A}_{\text {foam }} & \text { Area of the PVA foam (length } \mathrm{x} \text { width) }\left[\mathrm{cm}^{2}\right] \\ \mathrm{A}_{\text {ITFD }} & \begin{array}{l}\text { Area of the ITFD perpendicular to the } \\ \text { tracheostoma models' walls }\left[\mathrm{mm}^{2}\right]\end{array} \\ \mathrm{d}_{\mathrm{a}} & \begin{array}{l}\text { Average intratracheal diameter }[\mathrm{mm}] \\ \mathrm{F}_{\text {compression }}\end{array} \\ \mathrm{F}_{\text {ejection }} & \begin{array}{l}\text { Compression force }[\mathrm{N}] \\ \mathrm{P}_{\text {compression }}\end{array} \\ \mathrm{P}_{\text {ejection }} & \text { Pressure at compression }[\mathrm{mmHg}] \\ & \text { Pressure at ejection }[\mathrm{kPa}]\end{array}$

\section{INTRODUCTION}

In advanced stages of larynx cancer, a common treatment option is a total laryngectomy (TL). This is a surgical procedure in which the larynx (voice box) is removed and the trachea (windpipe) is connected to the base of the patient's neck, forming a permanent tracheostoma through which the patient subsequently breathes (Figure 1A). The TL procedure has an extensive impact on the patient's physical and psychological integrity, most apparent the loss of speech. [1] Therefore, multiple rehabilitation devices have been developed. A heat and moisture exchanger (HME) can be placed in the tracheostoma 
opening to condition the laryngectomized patient's inspired air. The HME can be manually occluded (Figure 1B) to direct airflow through a voice prosthesis into the esophagus (Figure 2 ), enabling tracheoesophageal speech. To improve dexterity and hygiene and to remove the emphasis on their disability, patients can use an additional automatic speaking valve (ASV) which closes automatically during speech exhalation, thus providing hands-free speech. Permanent hands-free speech is regarded as the optimal voice restoration after TL.

However, the current use of hands-free speech is limited to only $7-37.5 \%$ of laryngectomized patients [2-5], mainly due to problems with achieving effective ASV fixation in or around the tracheostoma opening. As a fixation method for the HME and ASV, the laryngectomized patients can use either a peristomal adhesive (around the tracheostoma, Figure 1A), or alternatively, an intratracheal cannula or button (inside the tracheostoma). Disadvantages associated with these fixation methods, to an extend caused by the large inter-patient variations in tracheostoma morphology [6-8], are: poor fit, adhesive peeling, button dislodgement, skin irritation, tissue traumatization and air leakage. [2-4,6,7,9] These fixation problems become more pronounced during hands-free speech, as the ASV exerts more stress on the fixation method without the natural backpressure during manual occlusion.

We have developed a novel Intratracheal Fixation Device (ITFD) as a possible alternative fixation method to improve the ASV fixation and ultimately compliance. The aim of this study was to evaluate the ITFD's feasibility in vitro, defined as an effective ASV fixation inside tracheostoma models for pressures corresponding to loud speech (endotracheal pressures of approximately $6 \mathrm{kPa})[10,11]$, without exerting excessive pressure on the tracheal tissue that could cause ischemic damage (an indirect trauma caused by constant and prolonged pressure $(>32 \mathrm{mmHg})$ on the soft tracheal tissue). [12]

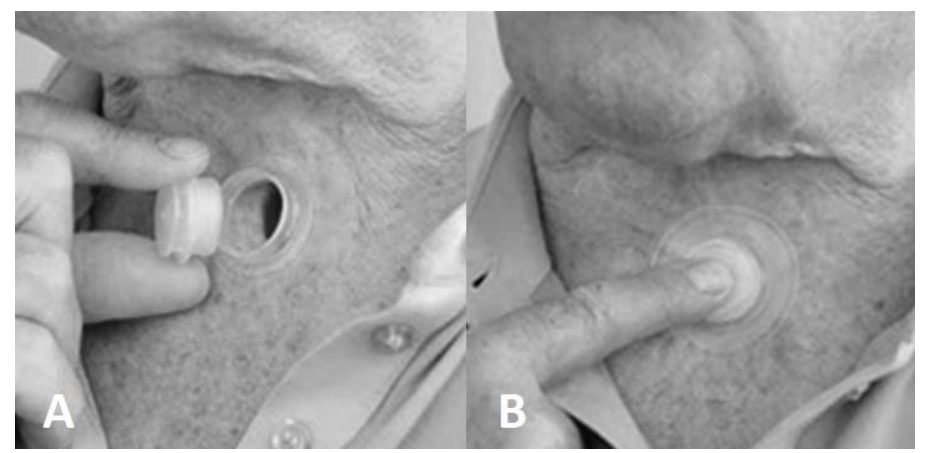

FIGURE 1: A) PERISTOMAL FIXATION OF AN HME IN THE TRACHEOSTOMA OPENING. B) OCCLUSION OF THE TRACHEOSTOMA (IN THIS CASE BY OCCLUDING THE HME) TO ENABLE TRACHEOESOPHAGEAL SPEECH.

\section{MATERIALS AND METHODS}

\subsection{The Intratracheal Fixation Device}

The intratracheal fixation device (ITFD) consists of a commercially available intratracheal button (Provox ${ }^{\circledR}$ Larybutton $^{\mathrm{TM}}$, Atos Medical AB, Malmö, Sweden) augmented by a hydrophilic polyvinyl acryl (PVA) foam exterior (Ivalon ${ }^{\circledR}$ Nasal Packing, Fabco, New England, CT, USA) around its shaft. This specific PVA foam material is deemed safe for application against the nasal mucosa, which is comparable to the tracheostoma environment, and its dimensions can safely be adjusted due to the material's non-shredding property. [13]

The PVA foam exterior expands and softens considerably under the influence of mucus and moisture from the exhaled air inside the tracheostoma opening (Figure 2). The expanded PVA foam exterior thereby adapts to the tracheostoma morphology, providing a deformable and potentially airtight fixation seal between the intratracheal button and the tracheostoma walls.

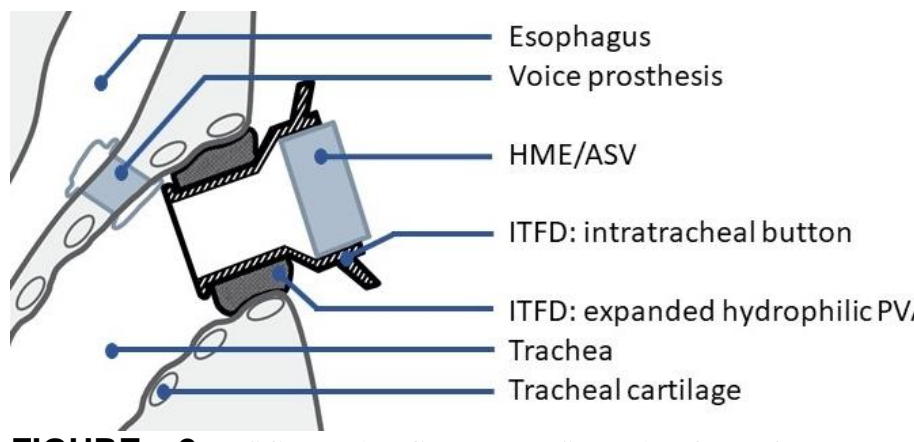

FIGURE 2: SCHEMATIC REPRESENTATION OF THE POSITIONING OF THE INTRATRACHEAL FIXATION DEVICE WITH THE HME/ASV INSIDE THE TRACHEOSTOMA.

\subsection{Exerted pressure of the PVA foam exterior}

To assess if the ITFD will not exert excessive pressures on the tracheal tissue when placed inside the tracheostoma, the relationship between the compression and exerted pressure of the expanded hydrophilic PVA foam was investigated.

Two different types of hydrophilic PVA foam samples were used:

- New Ivalon ${ }^{\circledR}$ Nasal Packings (Fabco, New England, CT, USA), fully hydrated with $5 \mathrm{ml}$ tap water to the expanded dimensions $80 \times 20 \times 15 \mathrm{~mm}$ (length $\mathrm{x}$ width $\mathrm{x}$ thickness).

- Rehydrated Ivalon ${ }^{\circledR}$ Nasal Packing (Fabco, New England, CT, USA), to simulate the material properties after longer ITFD's use. The PVA foam was hydrated and dried two days prior to this study and fully rehydrated with $5 \mathrm{ml}$ tap water to the expanded dimensions of $80 \times 20 \times 15 \mathrm{~mm}$ (length $\times$ width $\times$ thickness)

The expanded PVA foams were then individually compressed using a bench press (Zwick Z 5.0, ZwickRoell) with a loading rate of $2 \mathrm{~mm} / \mathrm{min}$, while recording the cross-head 
displacement and the load generated using a $200 \mathrm{~N}$ force cell (brand unknown). The bench press was calibrated beforehand by compressing a scale and recording both the measured load of the scale and the load cell (maximum deviation of $0.08 \mathrm{~N}$ ). To evenly distribute the exerted force over the expanded PVA foam, a light carbon fiber plate was placed between the PVA foam and the force cell.

The measured compression force on the expanded PVA foam (length $\mathrm{x}$ width) was converted to the exerted pressure (in $\mathrm{mmHg}$ ) using the following equation:

$$
P_{\text {compression }}=\frac{F_{\text {compression }}}{A_{\text {foam }}} * 75.0
$$

\subsection{Fixation of the ITFD}

To investigate whether the ITFD will remain fixated inside the tracheostoma during pressures corresponding to loud speech, the ejection force of the ITFD was evaluated in three different tracheostoma models:

- A straight PVC pipe with $\mathrm{d}=25 \mathrm{~mm}$, comparable to an average intratracheal tracheostoma diameter. [8]

- Two silicone rubber tracheostoma models with $d_{a}=25$ $\mathrm{mm}$ and $\mathrm{d}_{\mathrm{a}}=29.7 \mathrm{~mm}$, respectively (Figure 3 ). The models were made by casting two 3D-printed negative tracheostoma imprints, segmented from the CT scans of two laryngectomized patients, into silicone rubber (Zhermack, HT33 transparent, ShoreA 33). The silicone rubber has a hardness between that of soft tissue and tracheal cartilage. [14] The silicone rubber tracheostoma models were coated with water-soluble ultrasound gel (Aquasonic 100, Parker Laboratories Inc., New Jersey) to provide a friction coefficient comparable to a real tracheostoma.

ITFDs with varying foam exterior dimensions were made using a Provox ${ }^{\circledR}$ Larybutton $^{\mathrm{TM}}$ size 18/18 (shaft diameter and length in $\mathrm{mm}$, respectively) and adjusted Ivalon ${ }^{\circledR}$ Nasal Packings around its shaft (secured with suture string). The ITFDs were placed in each tracheostoma model, fixated in a vice-bench. Then, a tensile gauge $(5 \mathrm{~kg}-25 \mathrm{~g}$ Super Samson, Salter) was attached to the ITFD. The tensile gauge was slowly pulled away in a horizontal direction from the tracheostoma model, increasing the exerted force on the ITFD until the ITFD was ejected. The force at ejection was noted and each measurement was repeated three times. The measured ejection force was converted to the ejection pressure (in $\mathrm{kPa}$ ) on the area of the ITFD perpendicular to the tracheostoma models' walls using the following equation:

$$
P_{\text {ejection }}=\frac{F_{\text {ejection }}}{A_{\text {ITFD }}} * 1000
$$

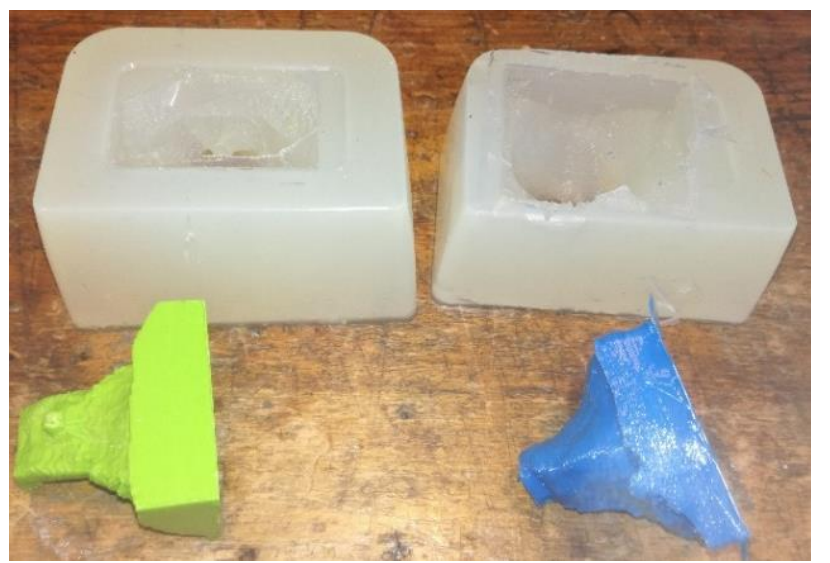

FIGURE 3: TWO SILICONE RUBBER TRACHEOSTOMA MODELS AND THEIR CORRESPONDING 3D-PRINTED NEGATIVE TRACHEOSTOMA IMPRINTS.

\section{RESULTS AND DISCUSSION}

As shown in Figure 4, the pressure generated by the hydrophilic PVA foam is almost linear to the percentage of total compression up to $50 \%$ respectively, when the PVA foam's pores have reached their maximum compression. When the PVA foam is compressed more than approximately $60 \%$ of its original thickness $(15 \mathrm{~mm})$, it exerts a pressure higher than $32 \mathrm{mmHg}$, which could potentially lead to ischemic damage. There is no significant difference in the load-displacement profiles between the rehydrated PVA foam and the newly hydrated PVA foam. Therefore, we assume the duration of the ITFD's use will not influence the fixation properties of the ITFD's PVA foam exterior.

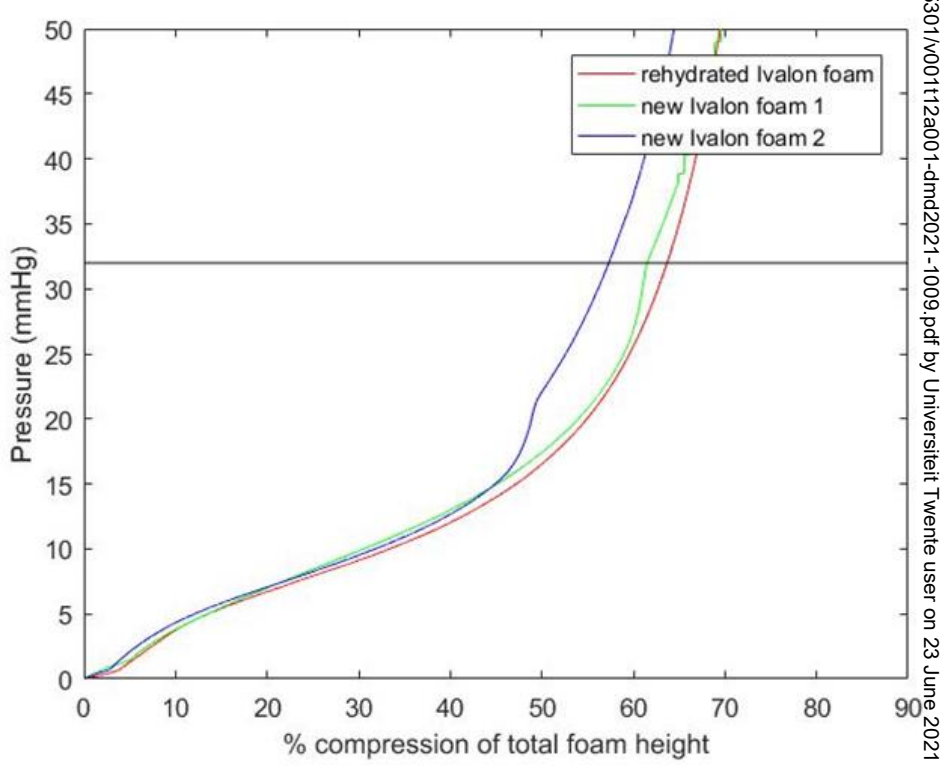

FIGURE 4: PRESSURE-COMPRESSION PROFILE OF THE HYDROPHILIC PVA FOAM DURING AXIAL COMPRESSION. THE HORIZONTAL LINE (AT 32 MMHG) REPRESENTS THE MAXIMUM PRESSURE ALLOWED TO AVOID ISCHEMIC DAMAGE IN TISSUE. 
As seen in Table 1, both the foam dimensions and the tracheostoma morphology influence the amount of ITFD fixation. Even a small amount of PVA foam increases the fixation of the ITFD. The variation in the foam exterior's length has more influence on the amount of fixation than the variation in the foam exterior's thickness. We conjecture that a PVA foam exterior thickness of approximately $7.5 \mathrm{~mm}$, in combination with different sizes of intratracheal button, can potentially provide both a safe and effective ASV fixation in a range of tracheostoma morphologies; it provides enough fixation to withstand pressures of loud speech (approximately $6 \mathrm{kPa}$ ) without exerting excessive pressure which could lead to ischemic damage to the tracheal tissue (if the compression $<60 \%$ of the PVA foam's original thickness).

Table 1: PRESSURE NEEDED TO EJECT THE ITFD WITH DIFFERENT FOAM EXTERIOR DIMENSIONS OUT OF THE TRACHEOSTOMA MODELS.

\begin{tabular}{|c|c|c|c|c|}
\hline \multicolumn{2}{|c|}{$\begin{array}{l}\text { Dimensions of } \\
\text { foam exterior }\end{array}$} & \multicolumn{3}{|c|}{$\begin{array}{c}\mathrm{P}_{\text {ejection }}[\mathrm{kPa}] \\
\text { (average compression of foam [\%]) }\end{array}$} \\
\hline 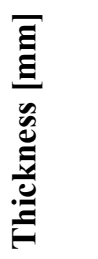 & 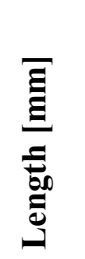 & 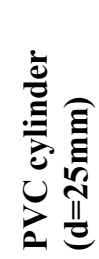 & 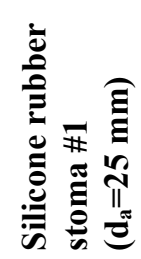 & 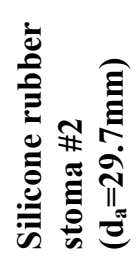 \\
\hline \multirow[t]{2}{*}{15} & 20 & $\begin{array}{l}14.8 \\
(76.7)\end{array}$ & $\begin{array}{l}24.8 \\
(76.7)\end{array}$ & $\begin{array}{l}14.5 \\
(60.9)\end{array}$ \\
\hline & 10 & $\begin{array}{l}4.3 \\
(76.7)\end{array}$ & $\begin{array}{l}14.2 \\
(76.7)\end{array}$ & $\begin{array}{l}10.0 \\
(60.9)\end{array}$ \\
\hline \multirow[t]{2}{*}{7.5} & 20 & $\begin{array}{l}9.8 \\
(53.3)\end{array}$ & $\begin{array}{l}13.3 \\
(53.3)\end{array}$ & $\begin{array}{l}12.2 \\
(21.8)\end{array}$ \\
\hline & 10 & $\begin{array}{l}2.7 \\
(53.3)\end{array}$ & $\begin{array}{l}10.7 \\
(53.3)\end{array}$ & $\begin{array}{l}8.3 \\
(21.8)\end{array}$ \\
\hline \multirow[t]{2}{*}{3.25} & 20 & $\begin{array}{l}3.7^{*} \\
(0)\end{array}$ & $\begin{array}{l}11.0 \\
(0)\end{array}$ & $\begin{array}{l}10.3 \\
(0)\end{array}$ \\
\hline & 10 & $\begin{array}{l}2.7^{*} \\
(0)\end{array}$ & $\begin{array}{l}10.8 \\
(0)\end{array}$ & $\begin{array}{l}7.7 \\
(0)\end{array}$ \\
\hline \multicolumn{2}{|c|}{ No foam } & n.a. & $\begin{array}{l}6.3 \\
(0)\end{array}$ & $\begin{array}{l}6.2 \\
(0)\end{array}$ \\
\hline
\end{tabular}

* Even though there is no compression of the PVA foam, the PVA foam exterior does provide extra friction for the intratracheal button to remain fixated for higher pressures inside the PVC cylinder.

Even though there are large inter-patient variations in tracheostoma morphology [6-8], the ITFD's deformable foam exterior could potentially resolve some disadvantages associated with the commercially available fixation methods without the need of a user-specific customization. [15]
However, the simplifications made in this study limit the reliability and comparability of these results. The exerted pressure of the ITFD's was not assessed in vivo on a curved tracheal wall. Due to the irregular morphology and presence of cartilage rings in the tracheostoma, the foam exterior might be distributed unevenly over the tracheostoma lumen. This could result in a higher amount of compression and thus exerted pressure at certain points in the tracheostoma, thus potentially ischemic damage. Furthermore, the measurements of the ITFD's fixation were only performed with one size (length and diameter) of intratracheal button, therefore its influence on the effectivity of the ITFD's fixation is unknown.

Additionally, the assessment of the user functionality, comfort and safety (e.g. potential restriction of the voice prosthesis or breathing lumen by the expanded PVA foam exterior) requires the support of a manufacturer and were outside the scope if this study. Therefore, a feasibility study in laryngectomized patients with varying tracheostoma morphologies is recommended as the next step.

\section{CONCLUSION}

This study demonstrates the feasibility of the ITFD in vitro that might improve stomal attachment of ASVs. The ITFD's deformable foam exterior may provide an effective fixation in most laryngectomized patients, compared to commercially available fixation methods, without the need for a user-specific customization, while potentially eliminating, or at least reducing the risk of discomfort or mucosal tissue traumatization. The results of a clinical feasibility study in laryngectomized patients are pending.

\section{ACKNOWLEDGEMENTS}

The Netherlands Cancer Institute's Department of Head and Neck Oncology and Surgery receives a research grant from Atos Medical AB (Malmö, Sweden), which contributes to the existing infrastructure for quality of life research of the Department of Head and Neck Oncology and Surgery.

\section{REFERENCES}

[1] Boscolo-Rizzo, P.M.F. et al. Long-term quality of life after total laryngectomy and postoperative radiotherapy versus concurrent chemoradiotherapy for laryngeal preservation. The Laryngoscope, 2008

[2] Hilgers, F.J.M. et al. Development and evaluation of a novel tracheostoma button and fixation system (Provox LaryButton and LaryClip adhesive) to facilitate hands-free tracheoesophageal speech. Acta Otolaryngol. 2009

[3] Lorenz, K.J. et al. Hands-free speech after surgical voice rehabilitation with a Provox voice prosthesis: experience with the Provox FreeHands HME tracheostoma valve system. Eur Arch Otorhinolaryngol. 2007 
[4] Op de Coul, B.M. et al. Compliance, quality of life and quantitative voice quality aspects of hands-free speech. Acta Otolaryngol. 2005

[5] Lansaat, L. et al. A prospective multicenter clinical feasibility study of a new automatic speaking valve for postlaryngectomy voice rehabilitation. Eur Arch OtoRhino-Laryngology, 2016

[6] Dirven, R. et al. 3D stereophotogrammetry for the assessment of tracheostoma anatomy. Acta Otolaryngol. 2008

[7] Ten Hallers. E.J. et al., Difficulties in the fixation of prostheses for voice rehabilitation after laryngectomy. Acta Otolaryngol. 2005

[8] Leemans, M. et al., Analysis of tracheostoma morphology, Acta-Otolaryngologica, 2017

[9] van der Houwen, E.B. et al., Does the patch fit the stoma? A study on peristoma geometry and patch use in laryngectomized patients, Clinical Otolaryngology, 2011

[10] Grolman, W. et al., Aerodynamic and Sound Intensity Measurements in Tracheoesophageal Voice. ORL J Otorhinolaryngol Relat Spec, 2007

[11] Schrijver, W.A.M.E., In Vivo Comparison of a New Tracheostomal Speech Valve with an Existing Valve. 2010. [12] Bhattacharya, Pressure ulcers: Current understanding and newer modalities of treatment. 2015.

[13] IVALON $®$ Ophthalmic Products, last viewed 08-072020. https://wwwshreyaasnet/pdf/FABCO_Cataloguepdf

[14] Goulding, J. and Crane. S. , Synthetic Anatomy: A study into multi-material $3 D$ printing and its application in prosthetics, INDN381, 2014.

[15] Lewin, J.S., et al., Modification of the LaryButton for Tracheoesophageal Speech. The Journal of prosthetic dentistry, 2009. 